\title{
Intuitionist Fuzzy almost Generalized Semi-pre Closed Mappings
}

\author{
D. Jayanthi \\ Department of Mathematics \\ NGM College, Pollachi \\ Tamilnadu, India
}

\begin{abstract}
In this paper we introduce intuitionistic fuzzy almost generalized semi-pre closed mappings and intuitionistic fuzzy almost generalized semi-pre open mappings. We investigate some of their properties. Also we provide the relation between intuitionistic fuzzy almost generalized semi-pre closed mappings and other intuitionistic fuzzy closed mappings.
\end{abstract}

\section{Keywords}

Intuitionistic fuzzy topology, intuitionistic fuzzy generalized semi-pre $T_{1 / 2}$ space, intuitionistic fuzzy almost generalized semi-pre closed mappings.

\section{INTRODUCTION}

After the introduction of fuzzy sets by Zadeh [13], there have been a number of generalizations of this fundamental concept. The notion of intuitionistic fuzzy sets introduced by Atanassov [1] is one among them. Using the notion of intuitionistic fuzzy sets, Coker [3] introduced the notion of intuitionistic fuzzy topological spaces. R. Santhi and D. Jayanthi [6] introduced the notion of intuitionistic fuzzy generalized semi-pre closed mappings and intuitionistic fuzzy generalized semi-pre open mappings. In this paper we introduce intuitionistic fuzzy almost generalized semi-pre closed mappings. We investigate some of its properties. Also we provide the relation between an intuitionistic fuzzy almost generalized semi-pre closed mapping and other intuitionistic fuzzy closed mappings.

\section{PRELIMINARIES}

Definition 2.1:[1] An intuitionistic fuzzy set (IFS in short) A in $\mathrm{X}$ is an object having the form

$\mathrm{A}=\left\{\left\langle\mathrm{x}, \mu_{\mathrm{A}}(\mathrm{x}), v_{\mathrm{A}}(\mathrm{x})\right\rangle / \mathrm{x} \in \mathrm{X}\right\}$ where the functions $\mu_{\mathrm{A}}: \mathrm{X}$ $\rightarrow[0,1]$ and $v_{\mathrm{A}}: \mathrm{X} \rightarrow[0,1]$ denote the degree of membership (namely $\mu_{A}(x)$ ) and the degree of non -membership (namely $v_{\mathrm{A}}(\mathrm{x})$ ) of each element $\mathrm{x} \in \mathrm{X}$ to the set $\mathrm{A}$, respectively, and 0 $\leq \mu_{\mathrm{A}}(\mathrm{x})+v_{\mathrm{A}}(\mathrm{x}) \leq 1$ for each $\mathrm{x} \in \mathrm{X}$.

Denote by IFS (X), the set of all intuitionistic fuzzy sets in $\mathrm{X}$.

Definition 2.2: [1] Let $A$ and $B$ be IFSs of the form $A=\{\langle x$, $\left.\left.\mu_{\mathrm{A}}(\mathrm{x}), v_{\mathrm{A}}(\mathrm{x})\right\rangle / \mathrm{x} \in \mathrm{X}\right\}$ and $\mathrm{B}=\left\{\left\langle\mathrm{x}, \mu_{\mathrm{B}}(\mathrm{x}), v_{\mathrm{B}}(\mathrm{x})\right\rangle / \mathrm{x} \in \mathrm{X}\right.$ \}.Then

(a) $\mathrm{A} \subseteq \mathrm{B}$ if and only if $\mu_{\mathrm{A}}(\mathrm{x}) \leq \mu_{\mathrm{B}}(\mathrm{x})$ and $v_{\mathrm{A}}(\mathrm{x}) \geq v_{\mathrm{B}}(\mathrm{x})$ for all $\mathrm{x} \in \mathrm{X}$

(b) $\mathrm{A}=\mathrm{B}$ if and only if $\mathrm{A} \subseteq \mathrm{B}$ and $\mathrm{B} \subseteq \mathrm{A}$

(c) $\mathrm{A}^{\mathrm{c}}=\left\{\left\langle\mathrm{x}, v_{\mathrm{A}}(\mathrm{x}), \mu_{\mathrm{A}}(\mathrm{x})\right\rangle / \mathrm{x} \in \mathrm{X}\right\}$ (d) $\mathrm{A} \cap \mathrm{B}=\left\{\left\langle\mathrm{x}, \mu_{\mathrm{A}}(\mathrm{x}) \wedge \mu_{\mathrm{B}}(\mathrm{x}), v_{\mathrm{A}}(\mathrm{x}) \vee v_{\mathrm{B}}(\mathrm{x})\right\rangle / \mathrm{x} \in \mathrm{X}\right\}$

(e) $\mathrm{A} \cup \mathrm{B}=\left\{\left\langle\mathrm{x}, \mu_{\mathrm{A}}(\mathrm{x}) \vee \mu_{\mathrm{B}}(\mathrm{x}), v_{\mathrm{A}}(\mathrm{x}) \wedge v_{\mathrm{B}}(\mathrm{x})\right\rangle / \mathrm{x} \in \mathrm{X}\right\}$

For the sake of simplicity, we shall use the notation $\mathrm{A}=\langle\mathrm{x}$, $\left.\mu_{\mathrm{A}}, v_{\mathrm{A}}\right\rangle$ instead of $\mathrm{A}=\left\{\left\langle\mathrm{x}, \mu_{\mathrm{A}}(\mathrm{x}), v_{\mathrm{A}}(\mathrm{x})\right\rangle / \mathrm{x} \in \mathrm{X}\right\}$.

The intuitionistic fuzzy sets $0 \sim=\{\langle\mathrm{x}, 0,1\rangle / \mathrm{x} \in \mathrm{X}\}$ and $1 \sim=$ $\{\langle\mathrm{x}, 1,0\rangle / \mathrm{x} \in \mathrm{X}\}$ are respectively the empty set and the whole set of $X$.

Definition 2.3: [11] The IFS $c(\alpha, \beta)=\left\langle x, c_{\alpha}, c_{1-\beta}\right\rangle$ where $\alpha$ $\in(0,1], \beta \in[0,1)$ and $\alpha+\beta \leq 1$ is called an intuitionistic fuzzy point(IFP for short) in $X$.

Note that an IFP $c(\alpha, \beta)$ is said to belong to an IFS $A=\left\langle x, \mu_{A}\right.$, $\left.v_{\mathrm{A}}\right\rangle$ of $\mathrm{X}$ denoted by $\mathrm{c}(\alpha, \beta) \in \mathrm{A}$ if $\alpha \leq \mu_{\mathrm{A}}$ and $\beta \geq v_{\mathrm{A}}$.

Definition 2.4:[3] An intuitionistic fuzzy topology(IFT for short) on $\mathrm{X}$ is a family $\tau$ of IFSs in X satisfying the following axioms.

(i) $0 \sim, 1 \sim \in \tau$

(ii) $\mathrm{G}_{1} \cap \mathrm{G}_{2} \in \tau$ for any $\mathrm{G}_{1}, \mathrm{G}_{2} \in \tau$

(iii) $\cup \mathrm{Gi} \in \tau$ for any family $\{\mathrm{Gi} / \mathrm{i} \in \mathrm{J}\} \subseteq \tau$.

In this case the pair $(X, \tau)$ is called an intuitionistic fuzzy topological space(IFTS in short) and any IFS in $\tau$ is known as an intuitionistic fuzzy open set (IFOS in short) in $\mathrm{X}$. The complement $\mathrm{A}^{\mathrm{c}}$ of an IFOS $\mathrm{A}$ in IFTS $(\mathrm{X}, \tau)$ is called an intuitionistic fuzzy closed set (IFCS in short) in X.

Definition 2.5:[3] Let $(X, \tau)$ be an IFTS and $A=\left\langle x, \mu_{A}, v_{A}\right\rangle$ be an IFS in $X$. Then the intuitionistic fuzzy interior and intuitionistic fuzzy closure are defined by

int $(\mathrm{A})=\cup\{\mathrm{G} / \mathrm{G}$ is an IFOS in $\mathrm{X}$ and $\mathrm{G} \subseteq \mathrm{A}\}$

$\operatorname{cl}(\mathrm{A})=\cap\{\mathrm{K} / \mathrm{K}$ is an IFCS in $\mathrm{X}$ and $\mathrm{A} \subseteq \mathrm{K}\}$

Note that for any IFS A in $(X, \tau)$, we have $\operatorname{cl}\left(\mathrm{A}^{\mathrm{c}}\right)=[\operatorname{int}(\mathrm{A})]^{\mathrm{c}}$ and $\operatorname{int}\left(\mathrm{A}^{\mathrm{c}}\right)=[\mathrm{cl}(\mathrm{A})]^{\mathrm{c}}[11]$.

Definition 2.6:[5] An IFS $A=\left\langle x, \mu_{A}, v_{A}\right\rangle$ in an $\operatorname{IFTS}(X, \tau)$ is said to be an

(i)intuitionistic fuzzy semi closed set(IFSCS in short) if $\operatorname{int}(\mathrm{cl}(\mathrm{A})) \subseteq \mathrm{A}$

(ii)intuitionistic fuzzy pre closed set(IFPCS in short) if $\operatorname{cl}(\operatorname{int}(\mathrm{A})) \subseteq \mathrm{A}$

(iii)intuitionistic fuzzy $\alpha$ closed $\operatorname{set}(\mathrm{IF} \alpha \mathrm{CS}$ in short) if $\operatorname{cl}(\operatorname{int}(\operatorname{cl}(\mathrm{A})) \subseteq \mathrm{A}$. 
The respective complements of the above IFCSs are called their respective IFOSs. The family of all IFSCSs, IFPCSs, and IF $\alpha$ CSs ( respectively IFSOSs, IFPOSs and IF $\alpha$ OSs ) of an $\operatorname{IFTS}(\mathrm{X}, \tau)$ are respectively denoted by $\operatorname{IFSC}(\mathrm{X}), \operatorname{IFPC}(\mathrm{X})$ and $\mathrm{IF} \alpha \mathrm{C}(\mathrm{X})$ (respectively $\mathrm{IFSO}(\mathrm{X})$, IFPO(X) and $\mathrm{IF} \alpha \mathrm{O}(\mathrm{X})$ )

Definition 2.7:[11] An IFS $A=\left\langle x, \mu_{A}, v_{A}\right\rangle$ in an IFTS $(X, \tau)$ is said to be an

(i) intuitionistic fuzzy semi-pre closed set (IFSPCS for short) if there exists an IFPCS B such that int $(\mathrm{B}) \subseteq \mathrm{A} \subseteq \mathrm{B}$.

(ii) intuitionistic fuzzy semi-pre open set (IFSPOS for short) if there exists an intuitionistic fuzzy pre open set (IFPOS for short) $\mathrm{B}$ such that $\mathrm{B} \subseteq \mathrm{A} \subseteq \mathrm{cl}(\mathrm{B})$.

The family of all IFSPCSs (respectively IFSPOSs) of an IFTS $(\mathrm{X}, \tau)$ is denoted by $\operatorname{IFSPC}(\mathrm{X})($ respectively $\operatorname{IFSPO}(\mathrm{X}))$.

Every IFSCS (respectively IFSOS) and every IFPCS (respectively IFPOS) is an IFSPCS (respectively IFSPOS). But the separate converses need not be true in general [11].

Note that an IFS $\mathrm{A}$ is an IFSPCS if and only if $\operatorname{int}(\operatorname{cl}(\operatorname{int}(\mathrm{A}))) \subseteq \mathrm{A}$ and an IFSPOS if and only if $\mathrm{A}$ $\subseteq \operatorname{cl}(\operatorname{int}(\operatorname{cl}(\mathrm{A})))$ [7].

Definition 2.8:[7]Let A be an IFS in an IFTS $(X, \tau)$. Then the semi-pre interior and the semi- pre closure of $\mathrm{A}$ are defined by

spint $(A)=\cup\{G / G$ is an IFSPOS in $X$ and $G \subseteq A\}$.

$\operatorname{spcl}(\mathrm{A})=\cap\{\mathrm{K} / \mathrm{K}$ is an IFSPCS in $\mathrm{X}$ and $\mathrm{A} \subseteq \mathrm{K}\}$.

Note that for any IFS $\mathrm{A}$ in $(\mathrm{X}, \tau)$, we have $\operatorname{spcl}\left(\mathrm{A}^{\mathrm{c}}\right)=$ $[\operatorname{spint}(A)]^{c}$ and $\operatorname{spint}\left(A^{c}\right)=[\operatorname{spcl}(A)]^{c}[7]$.

Definition 2.9:[10] An IFS A is an

(i) intuitionistic fuzzy regular closed set(IFRCS for short) if A $=\operatorname{cl}(\operatorname{int}(\mathrm{A}))$.

(ii) intuitionistic fuzzy generalized closed set(IFGCS for short) if $\operatorname{cl}(\mathrm{A}) \subseteq \mathrm{U}$ whenever $\mathrm{A} \subseteq \mathrm{U}$ and $\mathrm{U}$ is an IFOS.

The family of all IFRCSs and IFGCSs (respectively IFROSs

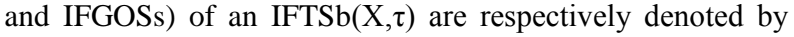
$\operatorname{IFRC}(X)$ and $\operatorname{IFGC}(X)($ respectively $\operatorname{IFRO}(X)$ and $\operatorname{IFGO}(X))$.

Definition 2.10:[7]An IFS A in an IFTS $(X, \tau)$ is said to be an intuitionistic fuzzy generalized semi-pre closed set(IFGSPCS for short) if $\operatorname{spcl}(\mathrm{A}) \subseteq \mathrm{U}$ whenever $\mathrm{A} \subseteq \mathrm{U}$ and $\mathrm{U}$ is an IFOS in $(\mathrm{X}, \tau)$.

Every IFCS, IFGCS, IFSCS, IFPCS, IFRCS, IF $\alpha C S$ and IFSPCS is an IFGSPCS but the separate converses may not be true in general [7].The family of all IFGSPCSs of an IFTS $(\mathrm{X}, \tau)$ is denoted by $\operatorname{IFGSPC}(\mathrm{X})$.

Definition 2.11:[6]Let $A$ be an IFS in an IFTS $(X, \tau)$. Then the generalized semi-pre interior and the generalized semi- pre closure of $\mathrm{A}$ are defined by

gspint $(A)=\cup\{G / G$ is an IFGSPOS in $X$ and $G \subseteq A\}$.

$\operatorname{gspcl}(\mathrm{A})=\cap\{\mathrm{K} / \mathrm{K}$ is an IFGSPCS in $\mathrm{X}$ and $\mathrm{A} \subseteq \mathrm{K}\}$.

Note that for any IFS $A$ in $(X, \tau)$, we have $\operatorname{gspcl}\left(\mathrm{A}^{\mathrm{c}}\right)=$ $[\operatorname{gspint}(\mathrm{A})]^{\mathrm{c}}$ and $\operatorname{gspint}\left(\mathrm{A}^{\mathrm{c}}\right)=[\mathrm{gspcl}(\mathrm{A})]^{\mathrm{c}}$

Remark 2.12:If an IFS A in an IFTS $(X, \tau)$ is an IFGSPCS in $\mathrm{X}$, then $\operatorname{gspcl}(\mathrm{A})=\mathrm{A}$. But the converse may not be true in general, since intersection does not exist in IFGSPCSs[7]
Remark 2.13:If an IFS A in an IFTS $(X, \tau)$ is an IFGSPOS in $\mathrm{X}$, then $\operatorname{gspint}(\mathrm{A})=\mathrm{A}$. But the converse may not be true in general, since union does not exist in IFGSPOSs[7].

Definition 2.14:[7] The complement $A^{c}$ of an IFGSPCS A in an $\operatorname{IFTS}(\mathrm{X}, \tau)$ is called an intuitionistic fuzzy generalized semi-pre open set (IFGSPOS for short) in X.

Every IFOS, IFGOS, IFSOS, IFPOS, IFROS, IF $\alpha \mathrm{OS}$ and IFSPOS is an IFGSPOS but the separate converses may not be true in general [7].The family of all IFGSPOSs of an IFTS $(\mathrm{X}, \tau)$ is denoted by $\operatorname{IFGSPO}(\mathrm{X})$.

Definition 2.15:[9] Let $c(\alpha, \beta)$ be an IFP of an IFTS (X, $\tau)$. An IFS A of $X$ is called an intuitionistic fuzzy neighborhood (IFN for short) of $c(\alpha, \beta)$ if there exists an IFOS B in $X$ such that $\mathrm{c}(\alpha, \beta) \in \mathrm{B} \subseteq \mathrm{A}$.

Definition 2.16:[8]If every IFGSPCS in $(X, \tau)$ is an IFSPCS in $(X, \tau)$, then the space can be called as an intuitionistic fuzzy semi- pre $\mathrm{T}_{1 / 2}$ space(IFSPT ${ }_{1 / 2}$ space for short).

Definition 2.17:[5] A map f: $\mathrm{X} \rightarrow \mathrm{Y}$ is called an intuitionistic fuzzy closed mapping (IFCM for short) if $\mathrm{f}(\mathrm{A})$ is an IFCS in $\mathrm{Y}$ for each IFCS A in $\mathrm{X}$.

Definition 2.18:[5] A map f: $\mathrm{X} \rightarrow \mathrm{Y}$ is called an

(i) intuitionistic fuzzy semi open mapping(IFSOM for short) if $\mathrm{f}(\mathrm{A})$ is an IFSOS in Y for each IFOS A in X.

(ii)intuitionistic fuzzyoopen mapping(IF $\alpha \mathrm{OM}$ for short) if $\mathrm{f}(\mathrm{A})$ is an IF $\alpha \mathrm{OS}$ in $\mathrm{Y}$ for each IFOS A in X.

(iii)intuitionistic fuzzy preopen mapping(IFPOM for short) if $\mathrm{f}(\mathrm{A})$ is an IFPOS in Y for each IFOS A in X.

Definition 2.19: The intuitionistic fuzzy semi closure and the intuitionistic fuzzyaclosure of an IFS A in an IFTS $(X, \tau)$ are defined by

$\operatorname{scl}(\mathrm{A})=\cap\{\mathrm{K} / \mathrm{K}$ is an IFSCS in $\mathrm{X}$ and $\mathrm{A} \subseteq \mathrm{K}\}$.

$\alpha \operatorname{cl}(\mathrm{A})=\cap\{\mathrm{K} / \mathrm{K}$ is an IF $\alpha \mathrm{CS}$ in $\mathrm{X}$ and $\mathrm{A} \subseteq \mathrm{K}\}$.

Definition 2.20:[6] Let $c(\alpha, \beta)$ be an IFP in $(X, \tau)$. An IFS A of $X$ is called an intuitionistic fuzzy semi neighborhood( IFSN for short) of $c(\alpha, \beta)$ if there is an IFSPOS B in X such that $\mathrm{c}(\alpha, \beta) \in \mathrm{B} \subseteq \mathrm{A}$.

Definition 2.21:[6] A mapping $\mathrm{f}: \mathrm{X} \rightarrow \mathrm{Y}$ is said to be an intuitionistic fuzzy generalized semi-pre closed mapping (IFGSPCM, for short) if $\mathrm{f}(\mathrm{A})$ is an IFGSPCS in $\mathrm{Y}$ for every IFCS $\mathrm{A}$ in $\mathrm{X}$.

Definition 2.22:[6] A mapping $f: X \rightarrow Y$ is said to be an intuitionistic fuzzy M-generalized semi-pre closed mapping(IFMGSPCM, for short) if $\mathrm{f}(\mathrm{A})$ is an IFGSPCS in $\mathrm{Y}$ for every IFGSPCS A in X.

Definition 2.23:[6] A mapping $\mathrm{f}: \mathrm{X} \rightarrow \mathrm{Y}$ is said to be an intuitionistic fuzzy almost generalized semi-pre continuous mapping(IFaGSP continuous mapping, for short) if $\mathrm{f}^{-1}(\mathrm{~A})$ is an IFGSPCS in $\mathrm{X}$ for every IFRCS $\mathrm{A}$ in $\mathrm{Y}$.

Definition 2.24: An IFS A is said to be an intuitionistic fuzzy dense(IFD for short) in another IFS $B$ in an IFTS $(X, \tau)$, if $\operatorname{cl}(\mathrm{A})=\mathrm{B}$. 


\section{INTUITIONISTIC FUZZY ALMOST GENERALIZED SEMI-PRE CLOSED MAPPINGS AND INTUTITIONISTIC FUZZY ALMOST GENERALIZED SEMI- PRE OPEN MAPPINGS}

In this section we introduce intuitionistic fuzzy almost generalized semi-pre closed mappings and intuitionistic fuzzy almost generalized semi-pre open mappings. We study some of their properties.

Definition 3.1:A map f: $X \rightarrow Y$ is called an intuitionistic fuzzy almost generalized semi-pre closed mapping (IFaGSPCM for short) if $\mathrm{f}(\mathrm{A})$ is an IFGSPCS in $\mathrm{Y}$ for each IFRCS A in X.

Example 3.2:Let $\mathrm{X}=\{\mathrm{a}, \mathrm{b}\}, \mathrm{Y}=\{\mathrm{u}, \mathrm{v}\}$ and $\mathrm{G}_{1}=\left\langle\mathrm{x},\left(0.5_{\mathrm{a}}\right.\right.$, $\left.\left.0.4_{\mathrm{b}}\right),\left(0.5_{\mathrm{a}}, 0.6_{\mathrm{b}}\right)\right\rangle, \mathrm{G}_{2}=\left\langle\mathrm{y},\left(0.2_{\mathrm{u}}, 0.3_{\mathrm{v}}\right),\left(0.8_{\mathrm{u}}, 0.7_{\mathrm{v}}\right)\right\rangle$. Then $\tau=$ $\left\{0_{\sim}, \mathrm{G}_{1}, 1_{\sim}\right\}$ and $\sigma=\left\{0_{\sim}, \mathrm{G}_{2}, 1_{\sim}\right\}$ are IFTs on $\mathrm{X}$ and $\mathrm{Y}$ respectively.. Define a mapping $\mathrm{f}:(\mathrm{X}, \tau) \rightarrow(\mathrm{Y}, \sigma)$ by $\mathrm{f}(\mathrm{a})=\mathrm{u}$ and $\mathrm{f}(\mathrm{b})=\mathrm{v}$. Then $\mathrm{f}$ is an IFaGSPCM.

Theorem 3.3:Every IFCM is an IFaGSPCM but not conversely.

Proof:Let $\mathrm{f}: \mathrm{X} \rightarrow \mathrm{Y}$ be an IFCM. Let $\mathrm{A}$ be an IFRCS in $\mathrm{X}$. Since every IFRCS is an IFCS, A is an IFCS in X. Then $\mathrm{f}(\mathrm{A})$ is an IFCS in Y. Since every IFCS is an IFGSPCS , $\mathrm{f}(\mathrm{A})$ is an IFGSPCS in $\mathrm{Y}$. Hence $\mathrm{f}$ is an IFaGSPCM.

Example 3.4:In Example $3.2 \mathrm{f}$ is an IFGSPCM but not an IFCM, since $\mathrm{G}_{1}{ }^{\mathrm{c}}=\left\langle\mathrm{x},\left(0.5 \mathrm{a}, 0.6_{\mathrm{b}}\right),\left(0.5_{\mathrm{a}}, 0.4_{\mathrm{b}}\right)\right\rangle$ is an IFCS in $\mathrm{X}$ but $f\left(G_{1}{ }^{c}\right)=\left\langle y,\left(0.5_{u}, 0.6_{v}\right),\left(0.5_{u}, 0.4_{v}\right)\right\rangle$ is not an IFCS in $Y$, since $\operatorname{cl}\left(f\left(\mathrm{G}_{1}{ }^{\mathrm{c}}\right)\right)=\mathrm{G}_{2}{ }^{\mathrm{c}} \neq \mathrm{f}\left(\mathrm{G}_{1}{ }^{\mathrm{c}}\right)$.

Theorem 3.5:Every IFSCM is an IFaGSPCM but not conversely.

Proof:Let $\mathrm{f}: \mathrm{X} \rightarrow \mathrm{Y}$ be an IFSCM. Let $\mathrm{A}$ be an IFRCS in $\mathrm{X}$. Since every IFRCS is an IFCS, A is an IFCS in X. Then $\mathrm{f}(\mathrm{A})$ is an IFSCS in Y. Since every IFSCS is an IFGSPCS , $\mathrm{f}(\mathrm{A})$ is an IFGSPCS in $\mathrm{Y}$. Hence $\mathrm{f}$ is an IFaGSPCM.

Example 3.6:Let $X=\{a, b\}, Y=\{u, v\}$ and $G_{1}=\left\langle x,\left(0.5_{a}\right.\right.$, $\left.\left.0.4_{\mathrm{b}}\right),\left(0.5_{\mathrm{a}}, 0.6_{\mathrm{b}}\right)\right\rangle, \mathrm{G}_{2}=\left\langle\mathrm{y},\left(0.5_{\mathrm{u}}, 0.4_{\mathrm{v}}\right),\left(0.2_{\mathrm{u}}, 0.3_{\mathrm{v}}\right)\right\rangle$. Then $\tau=$ $\left\{0_{\sim}, \mathrm{G}_{1}, 1_{\sim}\right\}$ and $\sigma=\left\{0_{\sim}, \mathrm{G}_{2}, 1_{\sim}\right\}$ are IFTs on $\mathrm{X}$ and $\mathrm{Y}$ respectively. Define a mapping $\mathrm{f}:(\mathrm{X}, \tau) \rightarrow(\mathrm{Y}, \sigma)$ by $\mathrm{f}(\mathrm{a})=\mathrm{u}$ and $\mathrm{f}(\mathrm{b})=\mathrm{v}$. Then $\mathrm{f}$ is an IFaGSPCM but not an IFSCM, since $\mathrm{G}_{1}{ }^{\mathrm{c}}=\left\langle\mathrm{x},\left(0.5 \mathrm{a}, 0.6_{\mathrm{b}}\right),\left(0.5_{\mathrm{a}}, 0.4_{\mathrm{b}}\right)\right\rangle$ is an IFCS in X but $\mathrm{f}\left(\mathrm{G}_{1}{ }^{\mathrm{c}}\right)=$ $\left\langle\mathrm{y},\left(0.5_{\mathrm{u}}, 0.6_{\mathrm{v}}\right),\left(0.5_{\mathrm{u}}, 0.4_{\mathrm{v}}\right)\right\rangle$ is not an IFSCS in $\mathrm{Y}$, since $\operatorname{int}\left(\operatorname{cl}\left(\mathrm{f}\left(\mathrm{G}_{1}{ }^{\mathrm{c}}\right)\right)\right)=1_{\sim} \subseteq \mathrm{f}\left(\mathrm{G}_{1}{ }^{\mathrm{c}}\right)$.

Theorem 3.7:Every IF $\alpha \mathrm{CM}$ is an IFaGSPCM but not conversely.

Proof:Let $\mathrm{f}: \mathrm{X} \rightarrow \mathrm{Y}$ be an IF $\alpha \mathrm{CM}$. Let $\mathrm{A}$ be an IFRCS in $\mathrm{X}$. Since every IFRCS is an IFCS, A is an IFCS in X. Then $\mathrm{f}(\mathrm{A})$ is an IF $\alpha C S$ in Y. Since every IF $\alpha C S$ is an IFGSPCS , $\mathrm{f}(\mathrm{A})$ is an IFGSPCS in $\mathrm{Y}$. Hence $\mathrm{f}$ is an IFaGSPCM.

Example 3.8:In Example $3.6 \mathrm{f}$ is an IFaGSPCM but not an IF $\alpha C M$, since $\mathrm{G}_{1}{ }^{\mathrm{c}}=\left\langle\mathrm{x},\left(0.5 \mathrm{a}, 0.6_{\mathrm{b}}\right),\left(0.5_{\mathrm{a}}, 0.4_{\mathrm{b}}\right)\right\rangle$ is an IFCS in $\mathrm{X}$ but $\mathrm{f}\left(\mathrm{G}_{1}{ }^{\mathrm{c}}\right)=\left\langle\mathrm{y},\left(0.5_{\mathrm{u}}, 0.6_{\mathrm{v}}\right),\left(0.5_{\mathrm{u}}, 0.4_{\mathrm{v}}\right)\right\rangle$ is not an IF $\alpha \mathrm{CS}$ in $\mathrm{Y}$, since $\mathrm{cl}\left(\operatorname{int}\left(\mathrm{cl}\left(\mathrm{f}\left(\mathrm{G}_{1}{ }^{\mathrm{c}}\right)\right)\right)\right)=1_{\sim} \subseteq \mathrm{f}\left(\mathrm{G}_{1}{ }^{\mathrm{c}}\right)$.

Theorem 3.9:Every IFPCM is an IFaGSPCM but not conversely.

Proof:Let $\mathrm{f}: \mathrm{X} \rightarrow \mathrm{Y}$ be an IFPCM. Let $\mathrm{A}$ be an IFRCS in $\mathrm{X}$. Since every IFRCS is an IFCS, A is an IFCS in $X$ Then $f(A)$ is an IFPCS in Y. Since every IFPCS is an IFGSPCS, $\mathrm{f}(\mathrm{A})$ is an IFGSPCS in $\mathrm{Y}$. Hence $\mathrm{f}$ is an IFaGSPCM.

Example 3.10:In Example $3.2 \mathrm{f}$ is an IFaGSPCM but not an IFPCM, since $\mathrm{G}_{1}{ }^{\mathrm{c}}=\left\langle\mathrm{x},\left(0.5 \mathrm{a}, 0.6_{\mathrm{b}}\right),\left(0.5_{\mathrm{a}}, 0.4_{\mathrm{b}}\right)\right\rangle$ is an IFCS in $\mathrm{X}$ but $\mathrm{f}\left(\mathrm{G}_{1}{ }^{\mathrm{c}}\right)=\left\langle\mathrm{y},\left(0.5_{\mathrm{u}}, 0.6_{\mathrm{v}}\right),\left(0.5_{\mathrm{u}}, 0.4_{\mathrm{v}}\right)\right\rangle$ is not an IFPCS in $Y$, since $\operatorname{cl}\left(\operatorname{int}\left(f\left(\mathrm{G}_{1}{ }^{\mathrm{c}}\right)\right)\right)=\mathrm{G}_{2}^{\mathrm{c}} \subseteq \mathrm{f}\left(\mathrm{G}_{1}{ }^{\mathrm{c}}\right)$.

Theorem 3.11:Every IFGSPCM is an IFaGSPCM but not conversely.

Proof:Let $\mathrm{f}: \mathrm{X} \rightarrow \mathrm{Y}$ be an IFGSPCM. Let $\mathrm{A}$ be an IFRCS in $X$. Since every IFRCS is an IFCS, $A$ is an IFCS in $X$ Then $\mathrm{f}(\mathrm{A})$ is an IFGSPCS in Y. Hence $\mathrm{f}$ is an IFaGSPCM.

Example 3.12:Let $X=\{a, b\}, Y=\{u, v\}$ and $G_{1}=\langle x,($ $\left.\left.0.2_{\mathrm{a}}, 0.2_{\mathrm{b}}\right),\left(0.4_{\mathrm{a}}, 0.4_{\mathrm{b}}\right)\right\rangle, \mathrm{G}_{2}=\left\langle\mathrm{x},\left(0.2_{\mathrm{a}}, 0_{\mathrm{b}}\right),\left(0.5_{\mathrm{a}}, 0.4_{\mathrm{b}}\right)\right\rangle, \mathrm{G}_{3}=$ $\left\langle\mathrm{y},\left(0.5_{\mathrm{u}}, 0.6_{\mathrm{v}}\right),\left(0.2_{\mathrm{u}}, 0_{\mathrm{v}}\right)\right\rangle$ and $\mathrm{G}_{4}=\left\langle\mathrm{y},\left(0.4_{\mathrm{u}}, 0.1_{\mathrm{v}}\right),\left(0.2_{\mathrm{u}}\right.\right.$, $\left.\left.0.1_{\mathrm{v}}\right)\right\rangle$. Then $\tau=\left\{0_{\sim}, \mathrm{G}_{1}, \mathrm{G}_{2}, 1_{\sim}\right\}$ and $\sigma=\left\{0_{\sim}, \mathrm{G}_{3}, \mathrm{G}_{4}, 1_{\sim}\right\}$ are IFTs on $\mathrm{X}$ and $\mathrm{Y}$ respectively. Define a mapping $\mathrm{f}:(\mathrm{X}, \tau)$ $\rightarrow(\mathrm{Y}, \sigma)$ by $\mathrm{f}(\mathrm{a})=\mathrm{u}$ andf $(\mathrm{b})=\mathrm{v}$. Then $\mathrm{f}$ is an IFaGSPM but not an IFGSPCM, since $\mathrm{G}_{2}{ }^{\mathrm{c}}=\left\langle\mathrm{x},\left(0.5_{\mathrm{a}}, 0.4_{\mathrm{b}}\right),\left(0.2_{\mathrm{a}}, 0_{\mathrm{b}}\right)\right\rangle$ is an IFCS in $X$ but $f\left(G_{2}{ }^{c}\right)=\left\langle y,\left(0.5_{u}, 0.4_{v}\right),\left(0.2_{u}, 0_{v}\right)\right\rangle$ is not an IFGSPCS in $\mathrm{Y}$, since $\mathrm{f}\left(\mathrm{G}_{2}{ }^{\mathrm{c}}\right) \subseteq \mathrm{G}_{3}$ but $\operatorname{spcl}\left(\mathrm{f}\left(\mathrm{G}_{2}{ }^{\mathrm{c}}\right)=1_{\sim} \subseteq \mathrm{G}_{3}\right.$.

Theorem 3.13 :Every IFMGSPCM is an IFaGSPCM but not conversely.

Proof:Let $\mathrm{f}: \mathrm{X} \rightarrow \mathrm{Y}$ be an IFMGSPCM. Let $\mathrm{A}$ be an IFRCS in $X$. Then $A$ is an IFGSPCS in X. By hypothesis $f(A)$ is an IFGSPCS in $\mathrm{Y}$. Therefore $\mathrm{f}$ is an IFaGSPCM.

Example 3.14:In Example $3.12 \mathrm{f}$ is an IFaGSPCM but not an IFMGSPCM, since $\mathrm{A}=\left\langle\mathrm{x},\left(0.4_{\mathrm{a}}, 0.2_{\mathrm{b}}\right),\left(0.2_{\mathrm{a}}, 0_{\mathrm{b}}\right)\right\rangle$ is an IFGSPCS in $\mathrm{X}$ but $\mathrm{f}(\mathrm{A})=\left\langle\mathrm{y},\left(0.4_{\mathrm{u}}, 0.2_{\mathrm{v}}\right),\left(0.2_{\mathrm{u}}, 0_{\mathrm{v}}\right)\right\rangle$ is not an IFGSPCS in $\mathrm{Y}$, since $\mathrm{f}(\mathrm{A}) \subseteq \mathrm{G} 3$ but $\operatorname{spcl}(\mathrm{f}(\mathrm{A}))=1_{\sim} \subseteq \mathrm{G}_{3}$.

The relation between various types of intuitionistic fuzzy closedness is given in the following diagram.

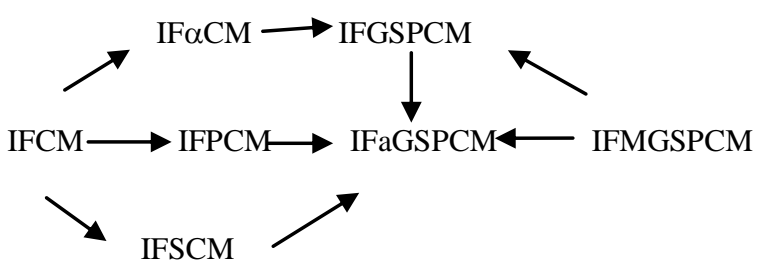

The reverse implications are not true in general in the above diagram.

Definition 3.15:A map $\mathrm{f}: \mathrm{X} \rightarrow \mathrm{Y}$ is called an intuitionistic fuzzy almost generalized semi-pre open mapping (IFaGSPOM for short) if $\mathrm{f}(\mathrm{A})$ is an IFGSPOS in $\mathrm{Y}$ for each IFROS $\mathrm{A}$ in $\mathrm{X}$.

Theorem 3.16:Let $\mathrm{f}: \mathrm{X} \rightarrow \mathrm{Y}$ be a mapping. Then the following are equivalent.

(i)f is an IFaGSPOM

(ii)f is an IFaGSPCM

Proof:Straightforward.

Theorem 3.17:Let $c(\alpha, \beta)$ be an IFP in X. A mapping $\mathrm{f}: \mathrm{X} \rightarrow \mathrm{Y}$ is an IFaGSPCM if for every IFOS $\mathrm{A}$ in $\mathrm{X}$ with $\mathrm{f}^{-1}(\mathrm{c}(\alpha, \beta)) \in \mathrm{A}$, there exists an IFOS B in $\mathrm{Y}$ with $\mathrm{c}(\alpha, \beta) \in \mathrm{B}$ such that $f(A)$ is IFD in $B$.

Proof:Let A be an IFROS in X. Then A is an IFOS in X. Let $\mathrm{f}^{-1}(\mathrm{c}(\alpha, \beta)) \in \mathrm{A}$, then there exists an IFOS $\mathrm{B}$ in $\mathrm{Y}$ such that 
$\mathrm{c}(\alpha, \beta) \in \mathrm{B}$ and $\mathrm{cl}(\mathrm{f}(\mathrm{A}))=\mathrm{B}$. Since B is an IFOS, $\operatorname{cl}(\mathrm{f}(\mathrm{A}))=\mathrm{B}$ is also an IFOS in Y. Therefore $\operatorname{int}(\operatorname{cl}(\mathrm{f}(\mathrm{A})))=\operatorname{cl}(\mathrm{f}(\mathrm{A}))$. Now

$\mathrm{f}(\mathrm{A}) \subseteq \mathrm{cl}(\mathrm{f}(\mathrm{A}))=\operatorname{int}(\mathrm{cl}(\mathrm{f}(\mathrm{A}))) \subseteq \mathrm{cl}(\operatorname{int}(\mathrm{cl}(\mathrm{f}(\mathrm{A}))))$. This implies $\mathrm{f}(\mathrm{A})$ is an IFSPOS in $\mathrm{Y}$ and hence an IFGSPOS in $\mathrm{Y}$. Thus $\mathrm{f}$ is an IFaGSPCM.

Theorem 3.18: Let $\mathrm{f}: \mathrm{X} \rightarrow \mathrm{Y}$ be a mapping where $\mathrm{Y}$ is an IFSPT1/2space. Then the following are equivalent:

(i)f is an IFaGSPCM.

(ii) $\operatorname{spcl}(f(A)) \subseteq f(\operatorname{cl}(A))$ for every IFSPOS A in $X$

(iii) $\operatorname{spcl}(f(A)) \subseteq f(c l(A))$ for every IFSOS $A$ in $X$

(iv)f $(A) \subseteq \operatorname{spint}(f(\operatorname{int}(\mathrm{cl}(\mathrm{A}))))$ for every IFPOS A in X.

Proof:(i) $\Rightarrow$ (ii)Let A be an IFSPOS in X. Then $\operatorname{cl}(\mathrm{A})$ is an IFRCS in $\mathrm{X}$. By hypothesis $\mathrm{f}(\mathrm{A})$ is an IFGSPCS in $\mathrm{Y}$ and hence is an IFSPCS in $\mathrm{Y}$, since $\mathrm{Y}$ is an IFSPT1/2 space. This implies $\operatorname{spcl}(\mathrm{f}(\mathrm{cl}(\mathrm{A})))=\mathrm{f} \quad(\operatorname{cl}(\mathrm{A}))$. Now $\operatorname{spcl}(\mathrm{f}(\mathrm{A}))$ $\subseteq \operatorname{spcl}(\mathrm{f}(\mathrm{cl}(\mathrm{A})))=\mathrm{f}(\mathrm{cl}(\mathrm{A}))$. Thus $\operatorname{spcl}(\mathrm{f}(\mathrm{A})) \subseteq \mathrm{f}(\mathrm{cl}(\mathrm{A}))$.

(ii) $\Rightarrow$ (iii) Since every IFSOS is an IFSPOS, the proof directly follows.

(iii) $\Rightarrow(\mathrm{i})$ Let $\mathrm{A}$ be an IFRCS in $\mathrm{X}$. Then $\mathrm{A}=\operatorname{cl}(\operatorname{int}(\mathrm{A}))$. Therefore $\mathrm{A}$ is an IFSOS in $\mathrm{X}$. By hypothesis, $\operatorname{spcl}(\mathrm{f}(\mathrm{A})$ ) $\subseteq \mathrm{f}(\mathrm{cl}(\mathrm{A}))=\mathrm{f}(\mathrm{A}) \subseteq \operatorname{spcl}(\mathrm{f}(\mathrm{A}))$. Hence $\mathrm{f}(\mathrm{A})$ is an IFSPCS and hence is an IFGSPCS in Y. Thus $\mathrm{f}$ is an IFaGSPCM.

(i) $\Rightarrow$ (iv)Let $A$ be an IFPOS in $X$. Then A $\subseteq \operatorname{int}(\operatorname{cl}(A))$. Since $\operatorname{int}(\operatorname{cl}(\mathrm{A}))$ is an IFROS in $\mathrm{X}$, by hypothesis, $\mathrm{f}(\operatorname{int}(\operatorname{cl}(\mathrm{A})))$ is an IFGSPOS in Y. Since $Y$ is an IFSPT1/2space, $f(\operatorname{int}(\operatorname{cl}(A)))$ is an IFSPOS in $\mathrm{Y}$. Therefore $\mathrm{f}(\mathrm{A}) \subseteq \mathrm{f}(\operatorname{int}(\mathrm{cl}(\mathrm{A})))$ $\subseteq \operatorname{spint}(\mathrm{f}(\operatorname{int}(\mathrm{cl}(\mathrm{A}))))$.

(iv) $\Rightarrow$ (i) Let $\mathrm{A}$ be an IFROS in X. Then $\mathrm{A}$ is an IFPOS in $\mathrm{X}$. By hypothesis, $\mathrm{f}(\mathrm{A}) \subseteq \operatorname{spint}(\mathrm{f}(\operatorname{int}(\mathrm{cl}(\mathrm{A}))))=\operatorname{spint}(\mathrm{f}(\mathrm{A})) \subseteq \mathrm{f}(\mathrm{A})$. This implies $\mathrm{f}(\mathrm{A})$ is an IFSPOS in $\mathrm{Y}$ and hence is an IFGSPOS in $\mathrm{Y}$. Therefore $\mathrm{f}$ is an IFaGSPCM.

Theorem 3.19:Let $\mathrm{f}: \mathrm{X} \rightarrow \mathrm{Y}$ be a mapping. Then $\mathrm{f}$ is an IFaGSPCM if for each IFP $c(\alpha, \beta) \in \mathrm{Y}$ and for each IFSPOS $B$ in $X$ such that $f-1(c(\alpha, \beta)) \in B, \operatorname{spcl}(f(B))$ is an IFSN of $\mathrm{c}(\alpha, \beta) \in \mathrm{Y}$.

Proof:Let $c(\alpha, \beta) \in \mathrm{Y}$ and let $\mathrm{A}$ be an IFROS in X. Then A is an IFSPOS in $\mathrm{X}$. By hypothesis $\mathrm{f}^{-1}(\mathrm{c}(\alpha, \beta)) \in \mathrm{A}$, that is $\mathrm{c}(\alpha, \beta)$ $\in \mathrm{f}(\mathrm{A})$ in $\mathrm{Y}$ and $\operatorname{spcl}((\mathrm{f}(\mathrm{A}))$ is an IFSN of $\mathrm{c}(\alpha, \beta)$ in $\mathrm{Y}$. Therefore there exists an IFSPOS B in $Y$ such that $c(\alpha, \beta)$ ) $\in \mathrm{B} \subseteq \operatorname{spcl}(\mathrm{f}(\mathrm{A}))$. We have $\mathrm{c}(\alpha, \beta) \in \mathrm{f}(\mathrm{A}) \subseteq \operatorname{spcl}(\mathrm{f}(\mathrm{A}))$. Now $\mathrm{B}$ $=\cup\{\mathrm{c}(\alpha, \beta) / \mathrm{c}(\alpha, \beta) \in \mathrm{B}\}=\mathrm{f}(\mathrm{A})$. Therefore $\mathrm{f}(\mathrm{A})$ is an IFSPOS in $\mathrm{Y}$ and hence an IFGSPOS in $\mathrm{Y}$. Thus $\mathrm{f}$ is an IFaGSPOM. Hence by Theorem $3.16 \mathrm{f}$ is an IFaGSPCM.

Theorem 3.20: Let $\mathrm{f}: \mathrm{X} \rightarrow \mathrm{Y}$ be a mapping. If $\mathrm{f}$ is an IFaGSPCM, then $g \operatorname{spcl}(\mathrm{f}(\mathrm{A}) \subseteq \mathrm{f}(\mathrm{cl}(\mathrm{A}))$ for every IFSPOS A in $\mathrm{X}$.

Proof:Let A be an IFSPOS in X. Then cl(A) is an IFRCS in $X$. By hypothesis $\mathrm{f}(\mathrm{cl}(\mathrm{A}))$ is an IFGSPCS in $\mathrm{Y}$. Then $\operatorname{gspcl}(\mathrm{f}(\mathrm{cl}(\mathrm{A}))=\mathrm{f}(\operatorname{cl}(\mathrm{A}))$. Now $\operatorname{gspcl}(\mathrm{f}(\mathrm{A})) \subseteq \operatorname{gspcl}(\mathrm{f}(\mathrm{cl}(\mathrm{A})))$ $\mathrm{f}(\operatorname{cl}(\mathrm{A}))$. That is $\operatorname{gspcl}(\mathrm{f}(\mathrm{A}) \subseteq \mathrm{f}(\operatorname{cl}(\mathrm{A}))$.

Corollary 3.21:Let $\mathrm{f}: \mathrm{X} \rightarrow \mathrm{Y}$ be a mapping. If $\mathrm{f}$ is an IFaGSPCM, then $\operatorname{gspcl}(\mathrm{f}(\mathrm{A}) \subseteq \mathrm{f}(\mathrm{cl}(\mathrm{A}))$ for every IFSOS $\mathrm{A}$ in $\mathrm{X}$.

Proof:Since every IFSOS is an IFSPOS, the proof directly follows from the Theorem 3.20.
Corollary 3.22:Let $\mathrm{f}: \mathrm{X} \rightarrow \mathrm{Y}$ be a mapping. If $\mathrm{f}$ is an IFaGSPCM, then $\operatorname{gspcl}(\mathrm{f}(\mathrm{A}) \subseteq \mathrm{f} \operatorname{cl}(\mathrm{A}))$ for every IFPOS $A$ in $\mathrm{X}$.

Proof:Since every IFPOS is an IFSPOS, the proof directly follows from the Theorem 3.20.

Theorem 3.23:Let $f: X \rightarrow Y$ be a mapping. If $f$ is an IFaGSPCM, then $\operatorname{gspcl}(\mathrm{f}(\mathrm{A})) \subseteq$

$\mathrm{f}(\mathrm{cl}(\operatorname{spint}(\mathrm{A})))$ for every IFSPOS A in X.

Proof:Let A be an IFSPOS in X. Then cl(A) is an IFRCS in $X$. By hypothesis, $\mathrm{f}(\mathrm{cl}(\mathrm{A}))$ is an IFGSPCS in $\mathrm{Y}$. Then $\operatorname{gspcl}(\mathrm{f}(\mathrm{A})) \subseteq \operatorname{gspcl}(\mathrm{f}(\mathrm{cl}(\mathrm{A})))=\mathrm{f}(\mathrm{cl}(\mathrm{A})) \subseteq \mathrm{f}(\operatorname{cl}(\operatorname{spint}(\mathrm{A})))$, since $\operatorname{spint}(\mathrm{A})=\mathrm{A}$.

Corollary 3.24:Let $\mathrm{f}: \mathrm{X} \rightarrow \mathrm{Y}$ be a mapping. If $\mathrm{f}$ is an IFaGSPCM, then $\operatorname{gspcl}(\mathrm{f}(\mathrm{A})) \subseteq \mathrm{f}(\operatorname{cl}(\operatorname{spint}(\mathrm{A})))$ for every IFSOS A in X.

Proof:Since every IFSOS is an IFSPOS, the proof directly follows from the Theorem 3.23 .

Corollary 3.25:Let $\mathrm{f}: \mathrm{X} \rightarrow \mathrm{Y}$ be a mapping. If $\mathrm{f}$ is an IFaGSPCM, then $\operatorname{gspcl}(\mathrm{f}(\mathrm{cl}(\mathrm{A}))) \subseteq \mathrm{f}(\operatorname{cl}(\operatorname{spint}(\mathrm{A})))$ for every IFPOS A in X.

Proof:Since every IFPOS is an IFSPOS, the proof directly follows from the Theorem 3.23.

Theorem 3.26:Let $f: X \rightarrow Y$ be a mapping. If $f(\operatorname{spint}(B))$ $\subseteq \operatorname{spint}(\mathrm{f}(\mathrm{B}))$ for every IFS B

in $\mathrm{X}$, then $\mathrm{f}$ is an IFaGSPOM.

Proof:Let $B \subseteq X$ be an IFROS. By hypothesis, $\mathrm{f}(\operatorname{spint}(\mathrm{B}))$ $\subseteq \operatorname{spint}(\mathrm{f}(\mathrm{B}))$. Since $\mathrm{B}$ is an IFROS, it is an IFSPOS in $\mathrm{X}$. Therefore $\operatorname{spint}(\mathrm{B})=\mathrm{B}$. Hence $\mathrm{f}(\mathrm{B})=\mathrm{f}(\operatorname{spint}(\mathrm{B})) \subseteq \operatorname{spint}(\mathrm{f}(\mathrm{B}))$ $\subseteq \mathrm{f}(\mathrm{B})$. This implies $\mathrm{f}(\mathrm{B})$ is an IFSPOS and hence an IFGSPOS in $\mathrm{Y}$. Thus $\mathrm{f}$ is an IFaGSPOM.

Theorem 3.27:Let $\mathrm{f}: \mathrm{X} \rightarrow \mathrm{Y}$ be a mapping. If $\operatorname{spcl}(f(B)) \subseteq f(\operatorname{spcl}(B))$ for every IFS $B$ in $X$, then $f$ is an IFaGSPCM.

Proof:Let $\mathrm{B} \subseteq \mathrm{X}$ be an IFRCS. By hypothesis, $\operatorname{spcl}(\mathrm{f}(\mathrm{B})) \subseteq \mathrm{f}(\operatorname{spcl}(\mathrm{B}))$. Since $\mathrm{B}$ is an IFRCS, it is an IFSPCS in $X$. Therefore $\operatorname{spcl}(B)=B$. Hence $\mathrm{f}(\mathrm{B})=\mathrm{f}(\operatorname{spcl}(\mathrm{B})) \supseteq \operatorname{spcl}(\mathrm{f}(\mathrm{B}))$ $\supseteq \mathrm{f}(\mathrm{B})$. This implies $\mathrm{f}(\mathrm{B})$ is an IFSPCS and hence an IFGSPCS in $\mathrm{Y}$. Thus $\mathrm{f}$ is an IFaGSPCM.

Theorem 3.28: Let $\mathrm{f}: \mathrm{X} \rightarrow \mathrm{Y}$ be a mapping where $\mathrm{Y}$ is an IFSPT $_{1 / 2}$ space. Then the following are equivalent.

(i)f is an IFaGSPOM

(ii)for each IFP $c(\alpha, \beta)$ in $\mathrm{Y}$ and each IFROS B in X such that $\mathrm{f}^{-1}(\mathrm{c}(\alpha, \beta)) \in \mathrm{B}, \operatorname{cl}(\mathrm{f}(\mathrm{cl}(\mathrm{B})))$ is an IFSN of $\mathrm{c}(\alpha, \beta)$ in $\mathrm{Y}$.

Proof:(i) $\Rightarrow$ (ii) Let $\mathrm{c}(\alpha, \beta) \in \mathrm{Y}$ and let $\mathrm{B}$ be an IFROS in $\mathrm{X}$ such that $\mathrm{f}^{-1}(\mathrm{c}(\alpha, \beta)) \in \mathrm{B}$. That is $\mathrm{c}(\alpha, \beta) \in \mathrm{f}(\mathrm{B})$. By hypothesis, $\mathrm{f}(\mathrm{B})$ is an IFGSPOS in $\mathrm{Y}$. Since $\mathrm{Y}$ is an IFSPT ${ }_{1 / 2}$ space, $\mathrm{f}(\mathrm{B})$ is an IFSPOS in $\mathrm{Y}$. Now $\mathrm{c}(\alpha, \beta) \in \mathrm{f}(\mathrm{B}) \subseteq \mathrm{f}(\mathrm{cl}(\mathrm{B}))$ $\subseteq \operatorname{cl}(\mathrm{f}(\mathrm{cl}(\mathrm{B})))$. Hence $\mathrm{cl}(\mathrm{f}(\mathrm{cl}(\mathrm{B})))$ is an IFSN of $\mathrm{c}(\alpha, \beta)$ in $\mathrm{Y}$.

(ii) $\Rightarrow(\mathrm{i})$ Let $\mathrm{B}$ be an IFROS in $\mathrm{X}$. Then $\mathrm{f}^{-1}(\mathrm{c}(\alpha, \beta)) \in \mathrm{B}$. This implies $\mathrm{c}(\alpha, \beta) \in \mathrm{f}(\mathrm{B})$. By hypothesis, $\operatorname{cl}(\mathrm{f}(\mathrm{cl}(\mathrm{B})))$ is an IFSN of $c(\alpha, \beta)$. Therefore there exists an IFSPOS $A$ in $Y$ such that $\mathrm{c}(\alpha, \beta) \in \mathrm{A} \subseteq \mathrm{cl}(\mathrm{f}(\mathrm{cl}(\mathrm{B})))$. Now $\mathrm{A}=\cup\{\mathrm{c}(\alpha, \beta) / \mathrm{c}(\alpha, \beta) \in \mathrm{A}\}$ $=\mathrm{f}(\mathrm{B})$. Thereforef(B) is an IFSPOS and hence an IFGSPOS in $\mathrm{Y}$. Thus $\mathrm{f}$ is an IFaGSPOM. 
Theorem 3.29: The following are equivalent for a mapping f: $\mathrm{X} \rightarrow \mathrm{Y}$ where $\mathrm{Y}$ is an $\mathrm{IFSPT}_{1 / 2}$ space.

(i)f is an IFaGSPCM

(ii) $\operatorname{spcl}(\mathrm{f}(\mathrm{A})) \subseteq \mathrm{f}(\alpha \mathrm{cl}(\mathrm{A}))$ for every IFSPOS A in $\mathrm{X}$

(iii) $\operatorname{spcl}(\mathrm{f}(\mathrm{A})) \subseteq \mathrm{f}(\alpha \mathrm{cl}(\mathrm{A}))$ for every IFSOS A in $\mathrm{X}$

(iv) $f(A) \subseteq \operatorname{spint}(f(\operatorname{scl}(A)))$ for every IFPOS A in $X$.

Proof:(i) $\Rightarrow$ (ii) Let A be an IFSPOS in X. Then $\operatorname{cl}(\mathrm{A})$ is an IFRCS in X. By hypothesis $\mathrm{f}(\mathrm{A})$ is an IFGSPCS in $\mathrm{Y}$ and hence is an IFSPCS in $\mathrm{Y}$, since $\mathrm{Y}$ is an IFSPT $_{1 / 2}$ space. This implies $\operatorname{spcl}(\mathrm{f}(\mathrm{cl}(\mathrm{A})))=\mathrm{f}(\mathrm{cl}(\mathrm{A}))$. Now $\operatorname{spcl}(\mathrm{f}(\mathrm{A}))$ $\subseteq \operatorname{spcl}(\mathrm{f}(\mathrm{cl}(\mathrm{A})))=\mathrm{f}(\mathrm{cl}(\mathrm{A}))$. Since $\operatorname{cl}(\mathrm{A})$ is an IFRCS, $\operatorname{cl}(\operatorname{int}(\operatorname{cl}(\mathrm{A})))=\operatorname{cl}(\mathrm{A})$. Therefore $\operatorname{spcl}(\mathrm{f}(\mathrm{A})) \subseteq \mathrm{f}(\mathrm{cl}(\mathrm{A}))=$ $(\operatorname{cl}(\operatorname{int}(\operatorname{cl}(\mathrm{A})))) \subseteq \mathrm{f}(\mathrm{A} \cup \operatorname{cl}(\operatorname{int}(\operatorname{cl}(\mathrm{A})))) \quad \subseteq \mathrm{f}(\alpha \operatorname{cl}(\mathrm{A}))$. Hence $\operatorname{spcl}(\mathrm{f}(\mathrm{A})) \subseteq \mathrm{f}(\alpha \mathrm{cl}(\mathrm{A}))$.

(ii) $\Rightarrow$ (iii) Let A be an IFSOS in X. Since every IFSOS is an IFSPOS, the proof is obvious.

(iii) $\Rightarrow$ (i) Let $A$ be an IFRCS in $X$. Then $A=\operatorname{cl}(\operatorname{int}(A))$. Therefore $\mathrm{A}$ is an IFSOS in $\mathrm{X}$. By hypothesis, $\operatorname{spcl}(\mathrm{f}(\mathrm{A}))$ $\subseteq \mathrm{f}(\alpha \mathrm{cl}(\mathrm{A})) \subseteq \mathrm{f}(\mathrm{cl}(\mathrm{A}))=\mathrm{f}(\mathrm{A}) \subseteq \operatorname{spcl}(\mathrm{f}(\mathrm{A}))$. That is $\operatorname{spcl}(\mathrm{f}(\mathrm{A}))=$ $f(A)$. Hence $f(A)$ is an IFSPCS and hence is an IFGSPCS in $\mathrm{Y}$. Thus $\mathrm{f}$ is an IFaGSPCM.

(i) $\Rightarrow$ (iv) Let $A$ be an IFPOS in $X$. Then A $\subset \operatorname{int}(\mathrm{cl}(\mathrm{A}))$. Since $\operatorname{int}(\mathrm{cl}(\mathrm{A}))$ is an IFROS in $\mathrm{X}$, by hypothesis, $\mathrm{f}(\operatorname{int}(\mathrm{cl}(\mathrm{A})))$ is an IFGSPOS in Y. Since $\mathrm{Y}$ is an IFSPT ${ }_{1 / 2}$ space,

$\mathrm{f}(\operatorname{int}(\operatorname{cl}(\mathrm{A})))$ is an IFSPOS in $\mathrm{Y}$. Therefore $\mathrm{f}(\mathrm{A}) \subseteq \mathrm{f}(\operatorname{int}(\mathrm{cl}(\mathrm{A})))$ $\subseteq \operatorname{spint}(\mathrm{f}(\operatorname{int}(\mathrm{cl}(\mathrm{A}))))=\operatorname{spint}(\mathrm{f}(\mathrm{A} \quad \operatorname{vint}(\operatorname{cl}(\mathrm{A}))))=$ $\operatorname{spint}(\mathrm{f}(\operatorname{scl}(\mathrm{A})))$. That is $\mathrm{f}(\mathrm{A}) \subseteq \operatorname{spint}(\mathrm{f}(\operatorname{scl}(\mathrm{A})))$.

(iv) $\Rightarrow$ (i) Let A be an IFROS in X. Then A is an IFPOS in X. By hypothesis, $f(A) \subseteq \operatorname{spint}(f(\operatorname{scl}(A)))$. This implies $f(A)$ $\subseteq \operatorname{spint}(\mathrm{f}(\mathrm{A} \cup \operatorname{int}(\mathrm{cl}(\mathrm{A})))) \subseteq \operatorname{spint}(\mathrm{f}(\mathrm{A} \cup \mathrm{A}))=\operatorname{spint}(\mathrm{f}(\mathrm{A} \quad))$ $\subseteq \mathrm{f}(\mathrm{A})$. Therefore $\mathrm{f}(\mathrm{A})$ is an IFSPOS in $\mathrm{Y}$ and hence an IFGSPOS in Y. Thus $\mathrm{f}$ is an IFaGSPCM, by Theorem 3.16.

Theorem 3.30:Let $\mathrm{f}: \mathrm{X} \rightarrow \mathrm{Y}$ be a mapping where $\mathrm{Y}$ is an IFSPT $_{1 / 2}$ space. If $\mathrm{f}$ is an IFaGSPCM, then $\operatorname{int}(\operatorname{cl}(\operatorname{int}(\mathrm{f}(\mathrm{B}))))$ $\subseteq \mathrm{f}(\operatorname{spcl}(\mathrm{B}))$ for every IFRCS B in $\mathrm{X}$

Proof:Let $\mathrm{B} \subseteq \mathrm{X}$ be an IFRCS. By hypothesis, $\mathrm{f}(\mathrm{B})$ is an IFGSPCS in $Y$. Since $Y$ is an IFSPT1/2space, $f(B)$ is an IFSPCS in $Y$. Therefore $\operatorname{spcl}(\mathrm{f}(\mathrm{B}))=\mathrm{f}(\mathrm{B})$. Now $\operatorname{int}(\operatorname{cl}(\operatorname{int}(f(B)))) \subseteq f(B) \cup \operatorname{int}(\operatorname{cl}(\operatorname{int}(f(B))))=\operatorname{spcl}(f(B))=f(B)$ $=\mathrm{f}(\operatorname{spcl}(\mathrm{B}))$. Hence int $(\operatorname{cl}(\operatorname{int}(\mathrm{f}(\mathrm{B})))) \subseteq \mathrm{f}(\operatorname{spcl}(\mathrm{B}))$.

Theorem 3.31:Let $\mathrm{f}: \mathrm{X} \rightarrow \mathrm{Y}$ be a mapping where $\mathrm{Y}$ is an IFSPT1/2space. If $\mathrm{f}$ is an IFaGSPCM, then $\mathrm{f}(\operatorname{spint}(\mathrm{B}))$ $\subseteq \mathrm{cl}(\operatorname{int}(\mathrm{cl}(\mathrm{f}(\mathrm{B}))))$ for every IFROS B in $\mathrm{X}$.

Proof:This theorem can be easily proved by taking complement in Theorem3.30.

Next we provide the characterization theorem for an IFaGSPOM.

Theorem 3.32:Let $\mathrm{f}: \mathrm{X} \rightarrow \mathrm{Y}$ be a bijective mapping. Then the following are equivalent.

\section{(i)f is an IFaGSPOM}

(ii)f is an IFaGSPCM

(iii)f-1is an IFaGSP continuous mapping.

Proof:(i) $\Leftrightarrow$ (ii) is obvious from the Theorem 3.16.

(ii) $\Rightarrow$ (iii) Let $\mathrm{A} \subseteq \mathrm{X}$ be an IFRCS. Then by hypothesis, $\mathrm{f}(\mathrm{A})$ is an IFGSPCS in $\mathrm{Y}$. That is $\left(\mathrm{f}^{-1}\right)^{-1}(\mathrm{~A})$ is an IFGSPCS in $\mathrm{Y}$. This implies $\mathrm{f}^{-1}$ is an IFaGSP continuous mapping.

(iii) $\Rightarrow$ (ii)Let $A \subseteq X$ be an IFRCS.Then by hypothesis $\left(\mathrm{f}^{-1}\right)^{-1}(\mathrm{~A})$ is an IFGSPCS in $\mathrm{Y}$. That is $\mathrm{f}(\mathrm{A})$ is an IFGSPCS in Y. Hence $\mathrm{f}$ is an IFaGSPCM.

\section{REFERENCES}

[1] Atanassov, K.,Intuitionistic fuzzy sets, Fuzzy Sets and Systems, 1986, 87- 96

[2] Chang, C., Fuzzy topological spaces, J. Math. Anal. Appl., 1968, 182-190.

[3] Coker, D., An introduction to intuitionistic fuzzy topological space,Fuzzy sets and systems, 1997, 81-89.

[4] Gurcay, H., Coker, D., and Haydar, Es. A., On fuzzy continuity in intuitionistic fuzzy topological spaces, The J.fuzzy mathematics, 1997, 365-378.

[5] Joung Kon Jeon, Young Bae Jun, and Jin Han Park, Intuitionistic fuzzyalpha-continuity and intuitionistic fuzzy pre continuity, International Journal of Mathematics and Mathematical Sciences, 2005, 30913101.

[6] Santhi, R. and Jayanthi, D., Intuitionistic fuzzy generalized semi-pre closed mappings(Submitted)

[7] Santhi, R. and Jayanthi, D., Intuitionistic fuzzy generalized semi-pre closed set(Accepted by Tripura Mathematical Society, Tripura)

[8] Santhi, R. and Jayanthi, D., Intuitionistic fuzzy generalized semi-pre continuous mappings(Accepted by The International journal of contemporary Mathematical\\ Sciences, Bulgaria)

[9] Santhi, R. and Jayanthi, D., Intuitionistic fuzzy almost generalized semi-pre continuous mappings(Submitted)

[10] Seok Jong Lee and Eun Pyo Lee,The category of intuitionistic fuzzy topological spaces, Bull. Korean Math. Soc. 2000, 63-76.

[11] Thakur, S. S and Rekha Chaturvedi, Regular generalized closed sets in intuitionistic fuzzy topological spaces, Universitatea Din Bacau,Studii Si Cercetari Stiintifice, Seria: Matematica, 2006, 257-272.

[12] Young Bae Jun and Seok- Zun Song, Intuitionistic fuzzy semi-pre opensets and Intuitionistic semi-pre continuous mappings, jour. of Appl. Math \& computing, 2005, 467474.

[13] Zadeh, L. A., Fuzzy sets, Information and control, 1965 , $338-35$ 